Bioscientia Medicina: Journal of Biomedicine \& Translational Research

Journal Homepage: www.bioscmed.com

\title{
The Effectiveness of Turmeric Extract (Curcuma domestica Val.) Against Fibroblast Cells in Socket Post Tooth Extraction
}

\section{Shieny Lokanata ${ }^{1 *}$, Sendyra Utama ${ }^{1}$, Mellisa Sim $^{1}$}

${ }^{1}$ Dentist Education Program, Faculty of Dentistry, Universitas Prima Indonesia, Medan, Indonesia

\author{
A R T I C L E I N F O \\ Keywords: \\ Curcumin \\ Fibroblast \\ Tooth extraction \\ Wound healing \\ Antioxidants
}

*Corresponding author:

Shieny Lokanata

E-mail address:

shienyluodrg@gmail.com

All authors have reviewed and approved the final version of the manuscript.

https://doi.org/10.37275/bsm.v6i4.490

\begin{abstract}
A B S T R A C T
Background. This study is an exploration to assess the potential of turmeric extract in the induction of fibroblast cell proliferation, where fibroblast cells are important cells in the process of repair and healing of wounds (socket wounds after tooth extraction). The antioxidants found in turmeric extract are believed to have potential in the initiation of growth factors which will then initiate the process of fibroblast cell activation, which in turn will play a role in wound healing. Methods: The research design in this study is an experimental study with a post-test-only approach with a control group design. The research subjects in this study were rats (Rattus norvegicus) Wistar strain, male sex, age 8-12 weeks, and body weight between 150-250 grams. A total of 30 white rats were grouped into 5 groups. Data analysis was carried out with the help of SPSS 25 software. First, a univariate analysis was performed to present the mean number of fibroblast cells and the standard deviation. Furthermore, an analysis was carried out to assess the difference in the mean number of fibroblast cells between groups using the one-way ANOVA test. Results: The results of the one-way ANOVA test showed that there were significant differences between the test groups. Giving $10 \%$ and $15 \%$ turmeric extract was seen to be more potent in the initiation of the number of fibroblast cells than the treatment group that received povidone-iodine. Conclusion: Turmeric extract (Curcuma domestica Val.) concentration of $15 \%$ was the most effective concentration as an effort to increase the number of fibroblast cells after tooth extraction in Wistar rats.
\end{abstract}

\section{Introduction}

Tooth extraction is done by removing the tooth from the socket into the alveolar bone which has the potential to cause post-extraction trauma or injury. Even in some cases, tooth extraction can cause complications during the healing process if not handled properly.1,2 There are phases of inflammation, proliferation, and remodeling/maturation as the three stages of wound healing. There are differences in the role of cells and the biological processes of each of the above stages. The inflammatory phase is characterized by the appearance of an inflammatory reaction and lasts about 0-3 days after injury. The proliferative phase is characterized by the re-formation of epithelial cells, fibroblasts and lasts about 3-21 days. The maturation/remodeling phase is the final phase of wound healing and lasts for 21 days-2 years and depends on the depth and extent of the wound.2,3 One indicator of the wound healing process is the number of fibroblast cells. Fibroblast cells are an important part of the proliferative phase of wound healing which plays a role in forming collagen, elastin, glycosaminoglycans formed by TGF- $\beta$ which induces the extracellular 
matrix to close the wound and continues to the phase of the wound reepithelialization process. ${ }^{3}$

Wound management is important to speed up the wound healing process. Infection can occur if the wound is not treated properly. So that wound medicine is needed to prevent the infection. However, commonly used wound medications such as povidone-iodine have side effects for hypersensitive patients. Curcuma domestica Val. or Curcuma longa Linn (turmeric) is a plant that is commonly used as herbal medicine. belongs the genus Curcuma which consists of the main compounds such as tannins, saponins, flavonoids, essential oils, and curcumin. In the literature, there are various in vivo and in vitro studies showing that curcumin has great potential to treat various inflammatory diseases. The content curcumin in turmeric rhizome (Curcuma domestica Val.) gives a distinctive color in the form of a yellow-orange color and has high antioxidant benefits with the aim of protecting cell damage caused by harmful free radicals to the body's tissues. ${ }^{4,5}$

This study is an exploratory study to assess the potential of turmeric extract in the induction of fibroblast cell proliferation, where fibroblast cells are important cells in the process of repair and healing of wounds (socket wounds after tooth extraction). The antioxidants found in turmeric extract are believed to have potential in the initiation of growth factors which will then initiate the process of fibroblast cell activation, which in turn will play a role in wound healing.

\section{Methods}

The research design in this study is an experimental study with a post-test-only approach with a control group design. The research subjects in this study were rats (Rattus norvegicus) Wistar strain, male sex, age 812 weeks, and body weight between 150-250 grams. A total of 30 rats were grouped into 5 groups, namely: K1 (negative control): given gel base, K2 (positive control): given povidone-iodine, K3: given Curcuma domestica Val extract gel. extract gel Curcuma domestica Val extract gel Curcuma domestica Val (turmeric) 15\%.

The turmeric extraction process is carried out by the maceration method. First, the turmeric rhizome is cleaned and washed to remove the existing dirt. Then the rhizome is chopped and dried. Next, the rhizome is crushed to obtain turmeric simplicia. A total of 600 grams of turmeric simplicia were soaked in a $70 \%$ ethanol solution of 6 liters, 3x24 hours. Furthermore, the macerate was evaporated using a rotary evaporator to obtain a thick extract. Next, the gel preparation was carried out. Carbopol weighing 0.1 grams was added to 20 milliliters of hot aquadest which was placed in a mortar, after 24 hours a gel mass was formed. Then stirred to form a turmeric extract gel.

The rats were then subjected to the extraction of the left incisors. First, the rats were anesthetized with ketamine $40 \mathrm{mg} / \mathrm{kg}$ BW. After the tooth extraction process is successful, then the test material is applied to the post-extraction tooth socket. After five days, the euthanasia process was carried out, then the postextraction socket tissue was evacuated and immersed in $10 \%$ Neutral Buffer Formalin solution. Next, the tissue was dehydrated by being put into an alcohol solution with a concentration gradient of $70 \%$ to $95 \%$ and a xylene solution. Next, the paraffinization process was carried out and the paraffinization slide was cut with a rotary microtome to obtain a tissue slide with a thickness of $5 \mathrm{~m}$. Then histopathological examination was carried out with Haematoxylin-Eosin (HE) staining to examine fibroblast cells.

Data analysis was carried out with the help of SPSS 25 software. First, a univariate analysis was performed to present the mean number of fibroblast cells and the standard deviation. Furthermore, an analysis was carried out to assess the difference in the mean number of fibroblast cells between groups using the one-way ANOVA test.

\section{Results}

Table 1 shows the results of the phytochemical test of turmeric extract. Turmeric extract contains alkaloid compounds, flavonoids. Saponins, tannins, and triterpenoids. Table 2 shows the comparison of the mean number of fibroblast cells between the treatment groups. The results of the one-way ANOVA test showed that there were significant differences between the test groups. Giving 10\% and 15\% turmeric extract was seen 
to be more potent in the initiation of the number of fibroblast cells than the treatment group that received povidone-iodine.

Table. 1 Phytochemical test of turmeric extract compounds (Curcuma domestica Val.)

\begin{tabular}{|c|c|c|}
\hline Secondary Metabolites & Reactants & Ethanol Extract \\
\hline Alkaloids & $\begin{array}{c}\text { Dragendroff, } \\
\text { Bouchardat, } \\
\text { Mayer, } \\
\text { Wagner }\end{array}$ & $\begin{array}{l}+ \\
+ \\
+ \\
+\end{array}$ \\
\hline Flavonoid & $\begin{array}{c}\mathrm{Mg}_{(\mathrm{s})}+\mathrm{HCl}_{(\mathrm{p})} \\
\mathrm{FeCl}_{3} 5 \% \\
\mathrm{NaOH} 10 \%^{\mathrm{H}_{2} \mathrm{SO}_{4(\mathrm{p})}} \\
\end{array}$ & $\begin{array}{l} \\
+ \\
- \\
-\end{array}$ \\
\hline Glycosides & Molish & - \\
\hline Saponins & Aquadest+Alcohol 96\% & + \\
\hline Tannins & $\mathrm{FeCl}_{3}$ & + \\
\hline Triterpenoids/Steroids & $\begin{array}{c}\text { Lieberman-Bourchat } \\
\text { Salkowsky }\end{array}$ & $\begin{array}{l}+ \\
+\end{array}$ \\
\hline
\end{tabular}

*+: positive; -: negative

Table 2. Comparison of the number of fibroblast cells between treatment groups

\begin{tabular}{|c|c|c|}
\hline Groups & Mean \pm SD & P-value \\
\hline Povidone-iodine & $108.1 \pm 15.80$ & \\
\hline Negative control & $63.5 \pm 17.62$ & \multirow{2}{*}{$<0.001^{*}$} \\
\hline Turmeric extract $5 \%$ & $101.5 \pm 19,03$ & \\
\hline Turmeric extract $10 \%$ & $129.8 \pm 29.58$ & \\
\hline Turmeric extract $15 \%$ & $156.9 \pm 25.70$ & \\
\hline
\end{tabular}

\section{Discussion}

Pathological conditions can impair normal anatomic functions and structures resulting in injury. There is an alternative treatment, namely traditional medicine in wound management. ${ }^{6}$ One of them is using turmeric (Curcuma domestica Val.). Turmeric (Curcuma domestica Val.) is known to be able to help the wound healing process as a type of useful herbal plant. This plant has the main compound in the form of curcumin and also has other compounds that are also known to play an important role in the healing process, namely essential oils, flavonoids, saponins, and tannins. In addition to curcumin, turmeric rhizome (Curcuma domestica Val.) also contains several other active compounds previously mentioned, namely tannins, saponins, flavonoids, and triterpenoids. These findings can also be seen from the results of the screening carried out in this study that turmeric extract (Curcuma domestica Val.) contains tannins, saponins, flavonoids, alkaloids, and triterpenoids. These active compounds in turmeric rhizome (Curcuma domestica Val) are secondary metabolites that have antioxidant, antiinflammatory, antifungal, and antiviral effects. ${ }^{7,8}$

One of the main keys that play a role in the wound closure process is fibroblasts which provide strength for wound contraction and unite the wound edges. ${ }^{1,7}$ In the wound healing process, fibroblast cells have a role to synthesize proteins, namely elastin and collagen which produce glycoproteins, proteoglycans, glycosaminoglycans, elasticity, reticular, and collagen through the extracellular matrix. In the inflammatory phase, leukocytes receive stimulation from macrophages and platelets derived from fibroblast growth factor 2 (FGF-2). ${ }^{3}$ Furthermore, in the 
proliferative phase of fibroblast cells will produce FGF2 which is continued in the synthesis of collagen. Then in the peak phase of fibroblast proliferation where fibroblasts will express FGF-2 so that the number of FGF-2 increases and supports the wound closure process. 9

Extract of Curcuma domestica Val. or turmeric can increase the proliferation of fibroblast cells. This supports the statement that describes the potential of turmeric (Curcuma domestica Val.) to be used as the main component of wound healing and treatment. The content of active compounds in Curcuma domestica Val. (turmeric) can increase the proliferation of fibroblast cells. ${ }^{10}$ In addition, the proliferation of fibroblast cells can also be increased thanks to the enhanced role of TGF- $\beta$ by the extract. In addition, turmeric extract has antioxidant and anti-inflammatory functions. The existence of this function causes the stages of the inflammatory process to be accelerated and stimulated so that the acceleration of fibroblast cells can occur. ${ }^{4}$

Groups of rats treated with Curcuma domestica Val extract. (turmeric) with a concentration of $15 \%$ in this study experienced a higher increase in fibroblasts than other groups of mice. These results are in line with the findings of a study that explains that high concentrations of turmeric extract ointment (Curcuma domestica Val.) can increase its effectiveness in accelerating wound healing. Other studies explain that Curcuma domestica Val. (turmeric) contains antioxidants that can increase the activity of antioxidant enzymes in the body so that it can help ward off free radicals and accelerate the wound healing process.

\section{Conclusion}

Turmeric extract (Curcuma domestica Val.) concentration of $15 \%$ was the most effective concentration as an effort to increase the number of fibroblast cells after tooth extraction in Wistar rats.

\section{References}

1. Yahya BH, Chausu G, Hamzani Y. Evaluation of wound healing following surgical extractions using the IPR Scale. Int Dental J. 2021; 71(2): 133-9.

2. Mardiyantoro F, Prasetyaningrum N, Rahmastuti HT. Histopathological characteristics of dental socket healing on collagen density following use of pangas catfish (Pangasius djambal) gelatin. Indonesian Dentistry Magazine. 2019; 5(3).

3. Gonzalez ACO, Costa TF, Andrade ZA, Medrado ARAP. Wound healing-A literature review. An Bras Dermatol. 2016; 91(5): 614-20.

4. Pawar RS, Toppo FA, Mandloi AS, Shaikh S. Exploring the role of curcumin containing ethanolic extract obtained from Curcuma longa (rhizomes) against retardation of wound healing process by aspirin. Indian $\mathrm{J}$ Pharmacol. 2015; 47(2): 160-6.

5. Akbik D, Ghadiri M, Chrzanowski W, Rohanizadeh R. Curcumin as a wound healing agent. Life Science. 2014; 116(1): 1-7.

6. Kurniawati A, Saputra DR, Cholid Z, Putra HK. Cacao seed (Theobroma cacao L.) extract gel effect on the neutrophil number after tooth extraction. Odonto Dental J. 2020; 7(1).

7. Barchitta M, Maugeri A, Favara G, Lio RMS, Evola G, et al. Nutrition and wound healing: an overview focusing on the beneficial effects of curcumin. IJMS. 2019; 20(5): 1119.

8. Miah MAH, Hasan M, Sarker YA, Alam MM, Juyena NS. Clinical evaluation of ethanolic extract of curcumin (Curcuma longa) on wound healing in Black Bengal goats. $\mathrm{J}$ Adv Vet Animal Res. 2017; 4(2).

9. des Araujo R, Lobo M, Trindade K, Silva DF, Pereira N. Fibroblast growth factors: a controlling mechanism of skin aging. Skin Pharm Phys. 2019; 32: 275-82.

10. Rahmad I, Milah NU, Kusumawardani A, Herliyani N, Sarwendah K, et al. The effect of turmeric (Curcuma domestica Val.) extract on the histopathological lesions of lung induced by cigarette smokes in rats. J Vet Science. $2015 ; 33(1)$. 